\title{
Research on the Optimization and Innovation of Computer Application Major in Higher Vocational Colleges
}

\author{
Pan Hongming \\ Chongqing Industry \& Trade Polytechnic, 408000 \\ hunter2011@foxmail.com
}

Keywords: Computer Application; Implementation process; Summary

\begin{abstract}
Compared with other majors, Computer Application has distinctive features, namely practical, comprehensive, application and very creative. Now the new model adopted in computer applications can adapt to the social needs of a wide range of computer applications professionals. By defining the project pedagogy, implementation steps, embodiment, problems and solutions, advantages, this paper summarizes a more systematic description of the application of computer application major in higher professional.
\end{abstract}

\section{Introduction}

The Core of "Project Based Learning" is the "Project", researchers explored the characteristics of computer applications for vocational students to meet professional computer applications related to professional positions (group) needs comprehensive coverage Syllabus and teaching requirements, and can really enhance students professional competence "Project" and verify in teaching practice and improvement, "project", is the main content of this thesis.

Project Approach, teachers and teaching activities through joint implementation of a complete project work carried out. It focuses attention on the central concepts and principles of a discipline designed to bring students into the meaningful task to complete the process, to enable students to actively learn autonomously carry out the construction of knowledge to the reality of learning to generate knowledge and train together the ability to target the highest achievement.

Approach to comply with the implementation of the project the following four principles:

Student-centered, and give full play to assist the role of teachers. In the teaching process, we should give full play to the initiative and creativity of students, for students based on the information their behavior to achieve self-feedback; at the same time cannot ignore the teacher's guidance, the teacher is to help the construction of meaning, facilitator, responsible for the entire teaching design and organization, directly involved in the discussion of students.

Selected projects are keys to learning. Select the item you want to contents of teaching as the basis for a realistic target for the material, it is necessary to include the teaching of basic knowledge, but also to mobilize the enthusiasm of students to solve problems. Teachers and students selected to participate in the project, teachers should pay attention to inspire students to take the initiative to found around the material, choose the difficulty for the project.

Creation of learning resources and collaborative learning environment is the most important work of teachers. Teachers need to give students multiple opportunities in different scenarios down the application of knowledge learned, full use of various means of modern educational technology learning resources to students. "Collaborative learning" is the key to meaning construction, so teachers should actively create student groups to discuss and exchange scenarios, so that students in the group common criticism of views and assumptions, negotiated settlement brightest difficulties, so that thinking and wisdom for each student group shared by students, so as to achieve all the students together to complete construction of meaning.

We should evaluate the students' learning level by defining the completion of the project. The ultimate goal of the learning process is to complete the construction of meaning, rather than teaching objectives. Teaching is not focusing on the teaching objectives, but around the completion of the project design, the construction of this center achieve significance to expand, so the 
evaluation of student learning should be based on the completion of the project to assess the situation.

\section{Implementation Steps}

According to the project design principles and teaching ideas, teaching pedagogy step design projects as follows:

1) According to the teaching situation creation requires the creation of content and the reality of the current situation of the students are learning basic environment close to the scene, that is, to introduce students to the need to solve real-world problems through a knowledge scene.

2) Demonstrations around the knowledge of the current study, in order to facilitate the students' knowledge transfer "requirements, select the appropriate small projects and demonstrate the settlement process of the project.

3) Independent exploration allows students to think independently, to understand the knowledge points, digestion and remedy demonstration projects, to address the practice project basis.

4) Determine the project team through social surveys, research and discussion, and to identify specific projects under the guidance of teachers.

5) Carry out collaborative learning group communication, discussion, group members division of labor, together to complete the project.

6) Study evaluated the effect of student learning directly from the case to complete the project to measure, including teacher evaluation, learning evaluation and self-assessment team of three parts.

7) As filed or practical teaching products of the project, the results of the application should have practical value as possible. Therefore, the results of the project work should be archived or applied to business and teaching practice in schools, software development can be applied to everyday life and learning departments or moderate. The above steps may vary depending on the choice of teaching content and projects.

\section{Implementation Plan}

Students clear objectives and requirements of the project after that start thinking about how to complete the project, to begin drafting embodiments training projects. Students in projects developed and implemented many training programs, teachers should be given proper guidance. Project implementation plan includes the following components.

1) Project Title: teacher assigned projects. It also can be chosen by the student teachers in several projects.

2) Group composed of staff: team members understand the composition, formation of collaborative learning team.

3) Project Objectives: issued directly by the teacher, the specific requirements of specific projects.

4) Project: Students through market research, digging their own knowledge and mutual exchanges, the formation of the project have been understanded.

5) Project tasks: students through discussion and reference teacher exploded views on the project, the total project is divided into multiple sub-tasks, sub-tasks clear goal interrelated and each sub-tasks.

6) Project Implementation Plan: Based ensure timely completion of the overall project, according to the complexity of each sub-task, to develop a timetable to complete the task, the head of each stage to the outcome of monitoring and inspection.

7) Personnel division: Honourable members of the group can be defined according to the characteristics, distribution sub-tasks, each member must undertake corresponding tasks.

8) The results show in the form of design: the results show a variety of forms, according to the characteristics of the project, select one or more to show the way. 


\section{Problems and Its Countermeasures}

Through surveys and visits can be seen in computer applications courses teaching pedagogy teaching effect application projects significantly better than traditional teaching methods. But traditional teaching methods have its own advantages, such as systemic lupus impart knowledge and so on. Only an effective combination, in order to better achieve the effect of classroom teaching, can achieve "both teaching and learning" to enhance students' professional ability. In the course of the project teaching should note the following issues:

1) Teachers. Project teaching teachers put forward higher requirements, carry out the project of teaching requires teachers to have the idea of this course a system of great creativity and resilience, to carefully observe the progress of each student's learning and interest in the development of master characteristics of each student and the corresponding proposed or designed both personality and focus on a comprehensive and balanced development of teaching programs, in order to arouse students' enthusiasm, or likely to cause some students are ignored consequences.

2) Select the item to be linked with the real world. Selected projects are key to the success of the teaching process, the topics to be in close contact with real life, such as: computer calculator, notepad program, drawing program and so on. That is a thing in real life (with learning and research value and is something the students are interested in) depth, the direct understanding and observation, students' interest in the project activities began spontaneously and expand the driving force. In the project selection process must consider the following questions: (1) how the project activities call students' prior knowledge? (2) This item can allow interested students. The ability to motivate students to collect information and to stimulate learning consciousness is important. (3) how to make students more aware of themselves and learn from each other? (4) How to get students to put the knowledge they have learned in real life linked? Whether (5) Project Description help build students' self-confidence?

3) Adjust the teaching process. Project teaching can effectively establish contact with the social life of the classroom, a suitable title is a reflection of real life, so that students learn more focused and practical, learned the skills needed for future employment, including practical ability, analytical skills, comprehensive ability, adaptability, communication skills, collaboration skills and the ability to solve practical problems, to enable students to vocational colleges to advance into social roles. Project Approach is a teaching strategy, whereby the guide students in real life things in-depth study. When we have the correct implementation of the project teaching, students' enthusiasm has been greatly inspired, consciously learning and quality completion of the project work. However, the specific implementation class according to the situation, the situation of individual students temporary adjustment.

4) The results of the project teaching evaluation. Project teaching job usually is a specific project, the project is to complete the process of studying the students themselves to explore the process, in order to learn all of those, summary after completion of the project is also very important, it includes a summary of ideas and skills summary. Thinking summarize the best way of thinking can help students clarify completion of the project, to find their own lack of theory; skills summary, "a given problem," it should be strongly recommended, regardless of the difficulty of each method should be presented to students, and then by teachers and students to evaluate the advantages and disadvantages of each method and scope. Allow students to participate in their own learning achievements evaluation; should be assessed in order to encourage students in the main, he pointed out the results of work deficiencies. Such learning students cannot reach the traditional classroom teaching effect on students self-confidence and other aspects of the effect is immeasurable, independent learning skills are improved. As a teacher vocational institutions should continue to learn and explore new teaching theory, reading books about the educational theory and practice.

\section{Advantages}

1) Help to improve student learning enthusiasm and initiative. Use Project Approach, teachers need to start each project for knowledge of teaching, students learning objectives clear, after 
completion of the theoretical knowledge, hands-on practice immediately, on the one hand have learned to use, there is a sense of accomplishment; on the other hand, the consolidation of the learned knowledge, and to be innovative in the existing basis.

2) Contribute to understanding of knowledge. Project Approach with vivid, specific examples of reproduction vague theoretical knowledge to make difficult problems to resolve in the problem solving process; deepen students' understanding of knowledge.

3) Train the students' ability to innovate. Oriented education ignored the cultivation of students 'innovative ability, emphasis on the study of knowledge, which focused on the current era of knowledge economy and innovation ability of people out of tune, and thus the quality of education we must strengthen the cultivation of students' ability to innovate. In the project teaching, to develop the potential of students, improve students' ability to self-monitoring and other aspects. Using discussion method can help students, such as analogy, deep understanding and interpretation of positive and negative arguments, predict situations and other more meaningful activities with deep thinking, and improve students' language ability and comprehensive. Meanwhile, the spirit of innovation is one of the contemporary social need professional capacity, innovative training and forging also can improve students' academic level vocational colleges low self-confidence and competitiveness to some extent.

4) Training the ability of students to multi-channel access to information. Traditional teaching, textbooks and teachers' lesson plans to become a major source of student access to information, this situation so that students narrow range of knowledge, easy to produce psychological dependence on the textbook, cannot adapt to the information society "knowledge explosion" situation. Thus, in the application of the project teaching through knowledge inquiry, task-driven, guide students through a variety of channels to obtain information, the students around a theme, widely accessible books, the Internet, and students to discuss and so on, to broaden the sources of knowledge, but also cultivate students each the ability to select types of information, processing of new requirements and this is the information age to vocational and technical vocational school students made and new challenges.

5) Training a new type of teacher-student relationship. In the process of teaching application projects, the relationship between teachers and students are no longer blindly teachers teach, students just listen to the traditional model, but the new model of equality between teachers and students exchange and interaction. Teacher is more of a mentor in the project development process activities of teachers and students of events and activities among students organically integrated to provide a new form of teacher-student interaction, help improve students' enthusiasm, equal exchange between teachers and students can truly reflect the democratic teaching.

6) Training the students' sense of cooperation, teamwork. Students must be done in joint activities to help each other, mutual supervision, in which each member should be responsible for the learning of other members, reflecting the man for me, I was conscious all the requirements. This allows students to have a psychological compatibility in a relationship, and establish harmonious interpersonal relationships, resulting in a positive impact on the formation and consolidation of the collective. In working towards achieving a job, students need to discuss with each other, argue, learn from each other, panel members focused on the wisdom, so as to achieve the desired learning objectives. Through collective finish the job, train the students collective consciousness, strengthening of the "woe" in relation to each other. You can imagine, with such a healthy, active professional quality of vocational students in the future will face any collective and team capability.

\section{Conclusion}

The process of exploring the project is to train students themselves, in order to learn all of those, summed up after the completion of the project are also very important. It should include a summary and thinking skills summary. Thinking summarize is the best way that can help students to clarify completion of the project, to find their theoretical deficiencies. In skills summary, "a given problem" should be strongly recommended, regardless of difficulty, each method should be presented to students, and then by the teachers and students to evaluate the advantages and 
disadvantages and scope of the various methods, so that students can learn more operating skills, fully absorb the essence of the entire project activities.

\section{References}

[1] Su-Zhi H. Project Approach in Electronic Technology Course Teaching. China Science and Technology Information, 2008, (02).

[2] Xu Chao. Investigate Automobile Application Technology Professional Project-Oriented Teaching Mode. Chinese Traffic Education Research Association 2008 Annual Traffic Education Science Excellent Thesis.

[3] Chen-Xiao Q. Vocational Computer Application Optimization and Innovation Analysis. Electronic Production, 2012 (10).

[4] Yang-Zhi W. Higher Vocational Computer Application Optimization and Innovation. Manufacturing Automation, 2011,33 (4). 79-83. 